\title{
The Relationship between Overfeeding and Wasting in Children.
}

\author{
By Vynne Borland, M.B., Ch.B., B.Sc.Glas., D.P.H.Lond.
}

\section{(ABSTRACT).}

VERFEEDING in children may occur in the three methods of feeding, namely :-

Breast-feeding; Supplementary or Complementary feeding ; Artificial feeding.

The effects and results in all are essentially similar. The transition from normal to wasting passes through the following stages in sequence, which may be definite or ill-defined :-

Regurgitation after feeds.

Disturbance of metabolic equilibrium.

Dyspepsia ; this may occur primarily after regurgitation.

Actual wasting or marasmus.

The departure from normal may be caused by :-

Too large quantities of a food containing proper proportions of constituents either from too frequent and irregular feeding or regular feeding with too much.

A relative overfeeding with a food containing a relatively high proportion of one or other constituent or all.

Symptoms usually begin with discomfort and regurgitation after feeds. The infant's tolerance and digestive powers may be increased and so effect a spontaneous cure. If not, the metabolic equilibrium is upset or dyspepsia appears with gastro-intestinal disturbance. The weight at first may show a rapid rise, then remains stationary for a time and finally begins to fall, with accompanying wasting to a lesser or greater degree according to the extent of the metabolic disturbance.

In children beyond infancy the symptoms as a rule are not so acute, but may be recognised as those of chronic gastro-intestinal indigestion resulting from a too liberal intake of carbohydrates and farinaceous foods or too much of a properly constituted diet and irregular meals.

The child becomes pale and anæmic with stationary weight or actual loss.

A paradoxical reaction is to be observed in the treatment, namely, increasing the food aggravates the symptoms and causes a further loss in weight. 
130 Relationship between Overfeeding and Wasting in Children.

Preventive Measures.

In breast-fed babies regulate the diet of the mother. Feed at regular intervals during the day and give no night feeds. Regulate the quantity according to the progress in weight and the character of the stools.

In supplementary or complementary feeding begin with small quantities. and allow 3 or 4 days to elapse before deciding to increase the quantity.

In hand-fed babies, do not give a food containing more than 4 per cent. fat or $\mathbf{8}$ per cent. carbohydrates. Increase quality or quantity or both slowly and deliberately. Avoid generally starchy foods until 9 months. Consider the environment of the child.

In older children give foods requiring mastication, avoiding too much. sloppy food. Give nothing between meals except water.

Avoid overfeeding in treatment of constipation.

The following took part in the discussion on this paper:-Dr. John Robertson (Birmingham); Dr. G. E. Oates (Bethnal Green); Dr. George Millson (Southwark); Miss Amy Hughes (London); Dr. E. Johnstone Jervis (Leeds): Mrs. E. Fuller (Dover); Dr. W. M. Branson (Halifax); Dr. D. C. Kirkhope (Tottenham); Mrs. Jenner (Folkestone); Mrs. S. J. Ebury (St. Pancras). 